\title{
Sustained Hedgehog signaling is required for basal cell carcinoma proliferation and survival: conditional skin tumorigenesis recapitulates the hair growth cycle
}

\author{
Mark E. Hutchin, ${ }^{1}$ Muhammed S.T. Kariapper ${ }^{1}$ Marina Grachtchouk, ${ }^{1}$ Aiqin Wang, ${ }^{1}$ Lebing Wei, ${ }^{1}$ \\ Donelle Cummings, ${ }^{1}$ Jianhong Liu, ${ }^{1}$ L. Evan Michael, ${ }^{1,2}$ Adam Glick, ${ }^{3}$ and Andrzej A. Dlugosz ${ }^{1,2,4}$ \\ ${ }^{1}$ Department of Dermatology and Comprehensive Cancer Center, and ${ }^{2}$ Cellular and Molecular Biology Graduate Program, \\ University of Michigan, Ann Arbor, Michigan 48109, USA; ${ }^{3}$ Laboratory of Cellular Carcinogenesis and Tumor Promotion, \\ National Cancer Institute, Bethesda, Maryland 20892, USA
}

Temporally and spatially constrained Hedgehog $(\mathrm{Hh})$ signaling regulates cyclic growth of hair follicle epithelium while constitutive Hh signaling drives the development of basal cell carcinomas (BCCs), the most common cancers in humans. Using mice engineered to conditionally express the Hh effector Gli2, we show that continued Hh signaling is required for growth of established BCCs. Transgene inactivation led to BCC regression accompanied by reduced tumor cell proliferation and increased apoptosis, leaving behind a small subset of nonproliferative cells that could form tumors upon transgene reactivation. Nearly all BCCs arose from hair follicles, which harbor cutaneous epithelial stem cells, and reconstitution of regressing tumor cells with an inductive mesenchyme led to multilineage differentiation and hair follicle formation. Our data reveal that continued Hh signaling is required for proliferation and survival of established BCCs, provide compelling support for the concept that these tumors represent an aberrant form of follicle organogenesis, and uncover potential limitations to treating BCCs using Hh pathway inhibitors.

[Keywords: Tumorigenesis; Hedgehog signaling; Gli2; basal cell carcinoma; hair follicle; organogenesis]

Received September 7, 2004; revised version accepted November 10, 2004.

Basal cell carcinoma (BCC) is the most common type of cancer in light-skinned individuals, and there are compelling data implicating uncontrolled activation of the Hedgehog (Hh) pathway (McMahon et al. 2003) in the pathogenesis of these tumors (Bale and Yu 2001) and several others (Pasca di Magliano and Hebrok 2003). During physiologic Hh signaling, Hh proteins bind to and antagonize the cell surface receptor Patched (Ptch), releasing Smoothened $(\mathrm{Smo})$ from Ptch-mediated inhibition. This leads to alterations in gene expression mediated by the Gli family of transcription factors (Gli1, Gli2, and Gli3) (Ingham and McMahon 2001). Ptch1 and Gli1 are two target genes consistently induced whenever the $\mathrm{Hh}$ pathway is activated (McMahon et al. 2003), making these transcripts reliable markers of both physiologic and pathologic Hh signaling activity.

Hh signaling is required for proliferation of hair follicle epithelium during development (St Jacques et al. 1998; Chiang et al. 1999) and postnatal hair cycles (Sato et al.

${ }^{4}$ Corresponding author.

E-MAIL dlugosza@umich.edu; FAX (734) 763-4575.

Article published online ahead of print. Article and publication date are at http://www.genesdev.org/cgi/doi/10.1101/gad.1258705.
1999; Wang et al. 2000), which include a growth phase (anagen), regression phase (catagen), and resting phase (telogen). Of the three Gli proteins, Gli2 appears to be the key transcriptional effector of Hh signaling in skin and other organs (Mo et al. 1997; Ding et al. 1998; Hardcastle et al. 1998; Matise et al. 1998; Motoyama et al. 1998; Bai et al. 2002; Mill et al. 2003). While Hh signaling activity in follicle epithelium is restricted to periods of active growth and is limited by the transient expression of Sonic hedgehog (Shh), this pathway is constitutively active in BCCs in the absence of ligand, due to mutations in PTCH or SMO (Hahn et al. 1996; Johnson et al. 1996; Xie et al. 1998). Several mouse models support the concept that aberrant Hh pathway activation is sufficient to drive development of BCCs or BCC-like tumors (Oro et al. 1997; Xie et al. 1998; Aszterbaum et al. 1999; Grachtchouk et al. 2000, 2003; Nilsson et al. 2000; Sheng et al. 2002). We previously reported that skin-targeted overexpression of Gli2 leads to the development of multiple BCCs in mice (Grachtchouk et al. 2000). Here we used a conditional mouse model to examine the role of Gli2 in established BCCs. Our findings support the notion that BCCs arise from hair follicles due to sustained, uncontrolled Hh pathway activity, which is re- 
quired in established BCCs for tumor cell proliferation and survival. We describe a small population of longlived, nonproliferative, residual tumor cells in regressed BCCs, which is capable of giving rise to growing tumors upon transgene reactivation. Our findings underscore the concept of cancer as a disease of aberrant organogenesis stemming from defects in critical "developmental" signaling pathways, and may have important clinical implications given current efforts to treat BCCs by interfering with deregulated $\mathrm{Hh}$ signaling.

\section{Results}

\section{BCCs arise from hair follicles in $\mathrm{K} 5-\mathrm{tTA}$; TRE-Gli2 bitransgenic mice}

While TRE-Gli2 (Fig. 1a) transgenic mice were indistinguishable from controls, multiple BCCs consistently arose on K5-tTA;TRE-Gli2 bitransgenic mice (Fig. 1b,c). Although tumor size was variable, BCCs were present by $6 \mathrm{mo}$ of age in $100 \%$ of bitransgenic mice (data not shown). BCCs arose on ears, extremities, and dorsal skin; however, the vast majority of BCCs developed on the tails (Fig. 1c).

Examination of skin sections from tumor-bearing mice revealed that BCCs arose almost exclusively from hair follicles (Fig. 1d-f). The hair follicle outer root sheath expresses abundant keratin 17 (K17) (Fig. 1g) but not keratin 1 or keratin 10 (K1, K10), which are markers of the follicle inner root sheath and suprabasal spinous cells in the epidermis (Fig. 1j). Bulbous proliferations of basaloid-appearing cells arose from the follicular epithelium and progressed to form obliquely oriented cellular masses expressing K17 (Fig. 1e,h). The histology of larger, fully developed BCCs mimics that of tumors seen in K5-Gli2 mice (Grachtchouk et al. 2000) and closely resembles human BCCs. BCCs were K17-positive and K1-negative and frequently contained focal areas of pigmentation within the tumor mass (Fig. 1f, red arrowhead) or surrounding stroma. Using in situ hybridization we assessed the expression of keratin 15 (K15), a marker of undifferentiated follicular epithelium, including stem cells, in adult mice (Lyle et al. 1999; Liu et al. 2003). We found that early BCCs consistently expressed this marker at high levels, while larger tumors express K15 mRNA at lower or occasionally undetectable levels (Fig. $1 \mathrm{~m}, \mathrm{n}$; data not shown). $\mathrm{K} 15$ is also expressed in a subset of human BCCs (Jih et al. 1999). Tumors arose from the follicular outer root sheath epithelium most commonly in the region of the infundibulum above the sebaceous gland (Fig. 1e,n) and were also seen in the proximal hair follicle (Fig. 1n).

\section{Inactivation of transgenic Gli2 leads to reduced hedgehog target gene expression}

We administered doxycycline to BCC-bearing K5-tTA; TRE-Gli2 double transgenic mice and obtained tissue over a 21-d period (Fig. 2a). In situ hybridization using a transgene-specific riboprobe confirmed efficient inactivation of the transgenic Gli2 mRNA following administration of doxycycline for $21 \mathrm{~d}$. Tumors from untreated mice expressed the transgene at high levels, and signal was absent in tumors from doxycycline-treated mice (Fig. 2b,g). As expected, expression of hedgehog target genes Gli1, Gli2, and Ptch1 was also up-regulated in untreated BCCs and dramatically reduced in treated tumors (Fig. 2b-k). K17 was expressed in both untreated and treated tumors, indicating the persistence of a subpopulation of viable tumor cells following transgene in- a
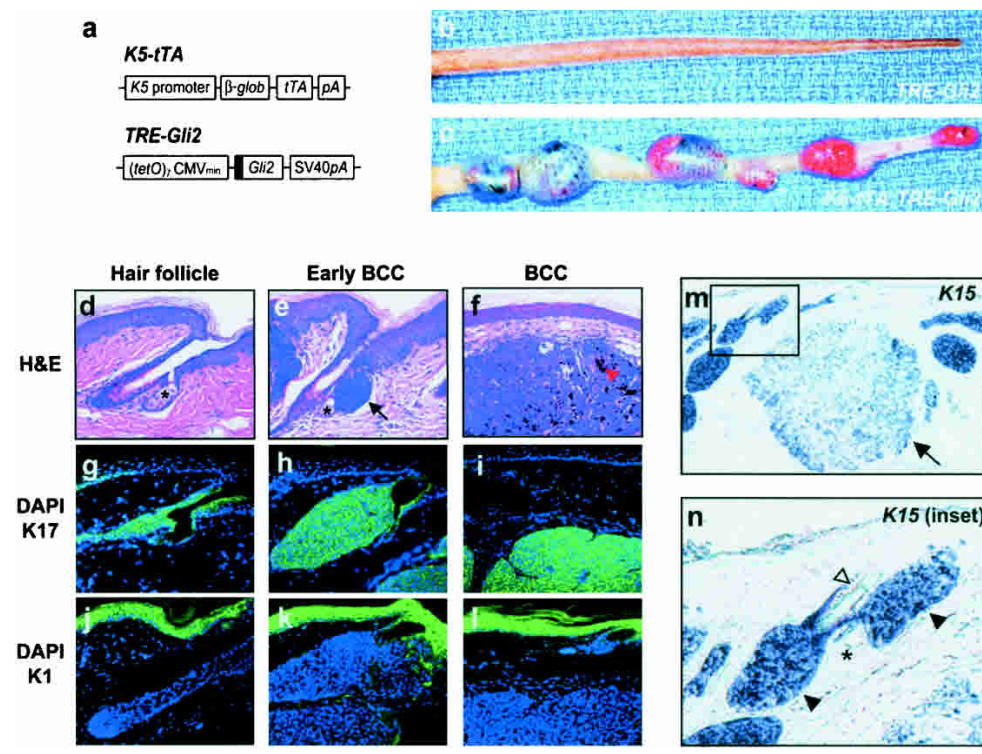

Early BCC

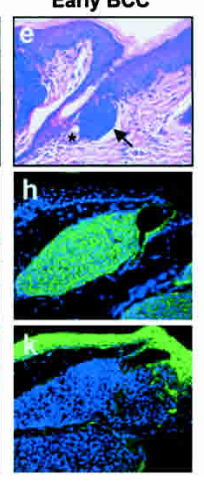

BCC

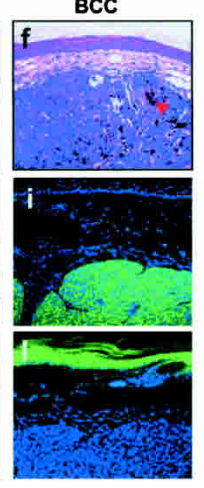

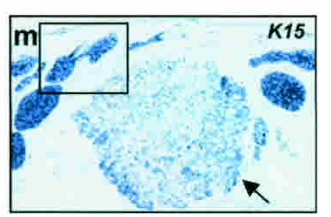

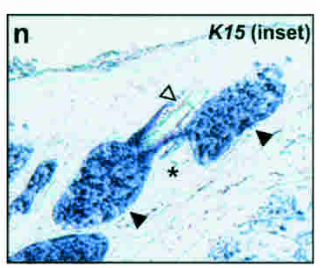

Figure 1. Follicle-derived BCC development in $\mathrm{K} 5$ tTA;TRE-Gli2 bitransgenic mice. (a) Schematic showing transgenic constructs designed to yield bitransgenic mice harboring a skin-targeted tetracycline transactivator $(K 5-t T A)$ and the tetracycline response element-Gli2 transgene (TRE-Gli2). Sequence encoding Flag epitope tag is shown by black box. $(b, c)$ Tails from single and bitransgenic mice, with BCCs in bitransgenic mouse only. $(d-f)$ Photomicrographs $(\mathrm{H} \& \mathrm{E}$ staining) of normal hair follicle and early BCC arising from hair follicle $(e$, black arrow), with sebaceous glands marked by asterisk $(d, e)$. (f) Established BCCs frequently contain focal BCC pigmentation (red arrowhead). (g-1) Immunofluorescence for keratins K17 and K1, both visualized with FITC (green) with nuclei counterstained with DAPI (blue). Normal hair follicle as well as BCCs express K17, while abundant expression of $\mathrm{K} 1$ is detected in the epidermis. $(m, n)$ In situ hybridization for the follicle marker K15 shows high expression in early tumors ( $n$, inset, black arrowheads) and lower expression in larger BCCs (m, black arrow). A hair shaft ( $n$, white arrowhead) is visible near the K15-positive early BCC, illustrating that early BCCs arise from hair follicles. Sebaceous gland marked by asterisk. 
Hutchin et al.

Figure 2. Trangene inactivation and hedge-hog target gene down-regulation following administration of doxycycline to BCC-bearing mice. (a) Schematic showing time course of transgene inactivation experiments. $(b-k)$ Transgene and hedgehog target gene expression in BCCs from untreated vs. doxycycline-treated (21 d) bitransgenic mice, assessed using digoxigenin-labeled antisense riboprobes. Efficient transgene inactivation was confirmed by undetectable levels of transgene-derived Gli2 mRNA $(g)$, which was accompanied by strong down-regulation of Gli1, Gli2, and Ptch1 $(h-j)$. (k) The presence of K17-positive cells in treated tumors indicates the persistence of a subset of cells in the absence of transgene expression and verifies mRNA integrity. Dashed lines indicate residual tumor cells in Day 21 regressed samples. $(d, i)$ Note that riboprobe for Gli2 recognizes both transgene-derived and endogenous Gli2. (1) Semiquantitative RT-PCR demonstrating inactivation kinetics of transgene-derived Gli2 (TREGli2) and hedgehog target genes in tumorbearing mice fed doxycycline. Note upregulation of hedgehog target genes Gli1, Gli2, Ptch1, Hip1, and Cyclins D1 and D2 in Day 0 BCC compared to nontransgenic mouse skin (Non Tg), and down-regulation following transgene inactivation.

activation and confirming RNA integrity (Fig. 2f,k). Semiquantitative RT-PCR using BCCs from mice treated for different lengths of time confirmed the in situ findings and revealed down-regulation of several additional hedgehog target genes (Fig. 21). The delayed attenuation of several target genes, compared to transgenederived Gli2 mRNA, suggests that a feedback loop may be operating which prevents immediate loss of all $\mathrm{Hh}$ signaling activity. Nevertheless, striking changes in BCC biology are evident by $3 \mathrm{~d}$ of doxycycline treatment (Fig. 3), suggesting that complete shut-down of Hh signaling activity is not required for bringing about tumor regression, as we previously proposed (Grachtchouk et al. 2003).

\section{Decreased tumor cell proliferation and increased apoptosis in regressing BCCs}

Transgene inactivation led to an $\sim 90 \%$ reduction in tumor volume over 3 wk (Fig. 3a-f,m). Immunofluorescence for Ki67 showed an $~ 15$-fold reduction in Ki67positive cells by $7 \mathrm{~d}$ (Fig. $3 \mathrm{~g}-\mathrm{i}, \mathrm{n}$ ). TUNEL staining showed massive induction of tumor cell apoptosis, which peaked after $3 \mathrm{~d}$ of transgene inactivation $(25 \%$ TUNEL-positive tumor cells) and subsequently returned toward baseline levels (Fig. 3j-1,o).

\section{Residual tumor cells in regressed BCCs are nonproliferative and express differentiation-specific cytokeratins}

Additional studies were performed to assess the longterm fate of residual tumor cells seen after 3 wk of doxy- cycline treatment (Figs. 2k, 3f). After an extended (5-mo) period of continuous doxycycline administration, this cell population persisted and appeared histologically similar to regressed tumor cells at earlier timepoints (Figs. 4a, 3f). Remarkably, all long-term regressed tumors immunofluorescence (Fig. 4b-e). Immunohistochemical staining for senescence-associated $\beta$-galactosidase activity did not suggest an increase in senescent cells (data not shown). All regressed tumors retained expression of the follicle outer root sheath marker K17 (Fig. 4f,g), but several markers for other hair follicle lineages (inner root sheath, hair shaft) were not detected (data not shown). Interestingly, a subset of these tumors $(40 \%, n=6 / 15)$ focally expressed K1 and K10, which are markers of the epidermal compartment and follicle inner root sheath (Fig. 4h,i; data not shown). Regressed BCCs did not express transgenic Gli2 by in situ hybridization but did express mRNA encoding $K 17$ (Fig. 4 j,, $\mathrm{k}$ ), in keeping with the immunofluorescence results and confirming RNA integrity.

\section{Regressing BCC cells give rise to multiple lineages} in a hair morphogenesis assay

The residual, K17-positive cells in regressed tumors were reminiscent of quiescent hair follicle stem cells in the regressed, telogen hair follicle, and the presence of $\mathrm{K} 1$ and $\mathrm{K} 10$ in a small number of cells suggested competence to differentiate into other lineages. We therefore tested the differentiation potential of regressing BCC cells by combining them with an inductive mesenchyexamined $(100 \%, n=15)$ were nonproliferative by $\mathrm{Ki} 67$ 


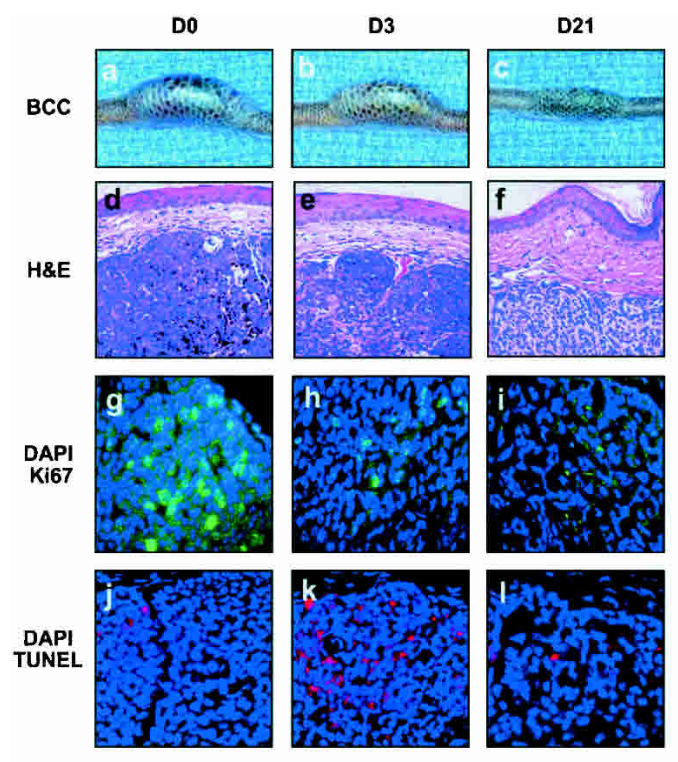

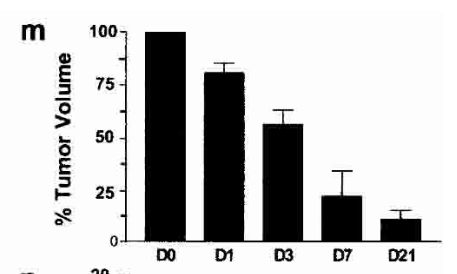

n

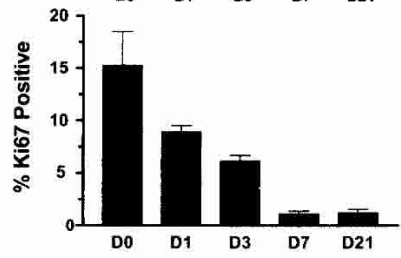

o

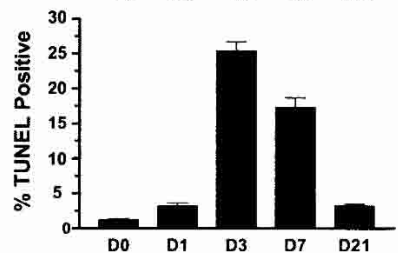

Figure 3. BCC regression following transgene inactivation is associated with reduced proliferation and increased apoptosis. $(a-c)$ Gross appearance of representative tail $\mathrm{BCC}$ demonstrating reduction in tumor size over the 21-d time course. $(d-f)$ $\mathrm{H} \& \mathrm{E}$-stained sections demonstrating histology of regressing BCCs. Note reduced cellularity of BCC at Day 21 (D21) relative to Day 0 (D0). (g-i) Immunofluorescence for the proliferation marker Ki67 (green) and associated nuclear counterstain DAPI (blue) at various time points. Note the dramatic reduction in proliferative nuclei over the 21-day period of regression. (j-1) TUNEL staining (red) as an indicator of apoptosis and nuclear counterstain DAPI (blue). Note the striking increase in apoptotic cells at Day 3 (D3) time point. (m) Quantitation of reduction in tumor volume over time. Each bar represents the average percentage of the initial (Day 0) tumor size for three BCCs from different mice. Standard errors indicated by bars. $(n, 0)$ Quantitation of the percentage of Ki67 or TUNEL-positive nuclei over time. Data are presented as average counts from three tumors per time point, with 10 high-powered fields counted per tumor for each time point. Standard errors indicated by bars.

mal cell population in a well characterized skin morphogenesis assay (Lichti et al. 1993; Kamimura et al. 1997; Prouty et al. 1997; Blanpain et al. 2004; Morris et al. 2004). Since efforts to isolate regressed tumor cells from doxycycline-treated mice met with limited success, we used BCC cells from untreated mice and transplanted them to doxycyline-treated immune-deficient hosts to inhibit transgene expression. Control cells from lacZexpressing Rosa26 mice (Zambrowicz et al. 1997) were used for mixing experiments, since they can be unequivocally distinguished from non-Rosa 26 cells by histochemical staining for $\beta$-galactosidase. Primary, inductive dermal cells from newborn Rosa26 mice were combined with BCC tumor cells, and injected subcutaneously into doxycycline-treated NOD-Scid mice. As a positive control, mice were injected with a mixture of Rosa26 dermal cells and Rosa26 keratinocytes, both isolated from newborn mice. After 3 wk, these control injections produced multiple hair follicles, sebaceous glands, and an epidermis-like epithelium. All epithelial cell types in these grafts expressed $\beta$-galactosidase and thus stained deep blue (Fig. 5a,c,e,g,i), confirming their derivation from Rosa26 epithelial cells. BCC tumor cells mixed with Rosa26 dermal cells also gave rise to multiple, normal-appearing epithelial lineages (Fig. 5b,d$, \mathrm{f}, \mathrm{h}, \mathrm{j})$. The regressing BCC cells contributed to hair bulbs containing $\beta$-galactosidase-negative matrix cells enveloping $\beta$-galactosidase-positive (Rosa26-derived) dermal papillae (Fig. 5d, open arrowhead), and scattered $\beta$-galactosidase-positive mesenchymal cells surrounding hair follicles. Regressing BCC tumor cells also contributed to the hair shaft, inner and outer root sheaths (Fig. 5f), and sebaceous lineage, forming morphologically mature se- baceous glands (Fig. 5h). Contaminating Rosa26 keratinocytes present in the dermal cell preparations were occasionally evident as small foci of blue-stained cells (Fig. 5b, black arrows), and represented $\sim 1 \%$ of all epithelial cells. In epithelial-lined cystic structures, suprabasal granules resembling keratohyaline granules, a marker for late stages of epidermal differentiation, appeared in controls (containing newborn skin epithelial cells) as well as in regressing BCC tumor cell assays (Fig. $5 i, j$ white arrows). Negative control grafts, using newborn Rosa26 dermal cells combined either with cells scraped from the underside of adult mouse tail skin or with keratinocytes isolated from adult mouse tail skin, failed to produce hair follicles.

\section{Regrowth of regressed tumors following transgene reactivation}

To assess the proliferative capacity of the residual tumor cells upon transgene reactivation, tumor-bearing $\mathrm{K5}-$ tTA;TRE-Gli2 mice were fed doxycycline for a period of 5 or 6 wk to inhibit transgene expression, followed by a 10-12-wk period off doxycycline to allow for transgene reactivation. Serial photographs revealed gross evidence of tumor regression during the $5 \mathrm{wk}$ of transgene inactivation, as expected (Fig. 6a). Following discontinuation of doxycycline, a subset of tumors resumed growth (Fig. 6a, white arrows). By in situ hybridization, "reactivated" tumors expressed transgenic Gli2 as well as K17 (Fig. $6 \mathrm{c}, \mathrm{d})$. The regressed-reactivated tumors were proliferative, based on Ki67 immunoreactivity, and also expressed K17 (Fig. 6e,f). 
Hutchin et al.

\section{Discussion}

Constitutive activation of the Hh pathway is the molecular hallmark of BCC and may be sufficient for the development of these common skin tumors. In this study, we show that continued Hh signaling is required for growth of established BCCs using a mouse model allowing conditional expression of Gli2. Transgene inactivation led to BCC regression that was accompanied by reduced proliferation and increased apoptosis, implicating Gli2 in the control of both survival and proliferation of tumor cells. Despite regression of the great majority of BCC cells, a population of quiescent cells persisted and could form tumors upon transgene reactivation. Moreover, reconstitution of regressing tumor cells with an inductive mesenchyme led to multilineage differentiation and formation of normal-appearing cutaneous epithelia. Our findings underscore the concept of cancer as a disease of aberrant organogenesis stemming from defects in critical "developmental" signaling pathways, and may have important clinical implications given current efforts to treat BCCs by interfering with deregulated Hh signaling.

Our results contrast with those described in other conditional models of cancer (Felsher 2003), in which apparently complete regression of tumor cells was observed following oncogene inactivation (Ewald et al. 1996; Chin et al. 1999; Felsher and Bishop 1999; Pelengaris et al. 1999, 2002; Huettner et al. 2000; Clark et al. 2001; D'Cruz et al. 2001; Fisher et al. 2001; Wang et al. 2001; Jain et al. 2002; Moody et al. 2002; Gunther et al. 2003; Karlsson et al. 2003). Even brief transgene inactivation in highly malignant cells can lead to irreversible loss of neoplastic potential and acquisition of a differentiated phenotype (Jain et al. 2002). While the ease of monitoring macroscopic BCCs facilitated the identification of residual tumor cells in regressed BCCs, a small number of remaining cells may also persist in other tumor models but may escape initial detection. Indeed, this could explain the observation that seemingly efficient tumor regression is sometimes followed by the emergence of transgene-independent tumors, presumably due to the acquisition of additional genetic alterations in previously transgene-dependent tumor cells (Chin et al. 1999; Felsher and Bishop 1999; D'Cruz et al. 2001; Moody et al. 2002; Gunther et al. 2003; Karlsson et al. 2003). In light of these reports, it is notable that we never observed transgene-independent BCC recurrence, even in K5tTA;TRE-Gli2 mice that had been maintained on doxycycline to suppress transgene expression for over a year (data not shown). This finding is in keeping with the benign clinical behavior of human BCCs: These tumors do not appear to undergo malignant progression and thus almost never metastasize (Miller 1995).

Inactivation of transgenic Gli2 resulted in BCC regression with the persistence of a nonproliferative, quiescent population of cells that could be reactivated to produce growing tumors following transgene reactivation (Fig. 6). This finding raises the interesting possibility that these cells represent cancer stem cells: the small subset of cells within a tumor that is actually tumorigenic, is characterized by high proliferative potential, and gives rise to both tumorigenic cells and nontumorigenic tumor cells exhibiting varying degrees of terminal differentiation (Pardal et al. 2003). However, definitive evidence for the existence of cancer stem cells in BCCs is lacking, as there is currently no means of effectively isolating and characterizing BCC subpopulations to test for differences in tumorigenic and proliferative potential, either in vitro or in vivo. In addition, it is not yet clear whether the concept of cancer stem cells is applicable to those tumors, including BCCs, that consist of relatively homogeneous populations of "undifferentiated" tumor cells.

BCC may be a unique example of cancer behaving more like a hyperplastic organ than true malignancy, as this tumor type remains localized and, like the hair fol-
Figure 4. Long-term persistence of nonproliferative cell population in regressed BCCs. (a) Photomicrograph illustrating typical morphology of persistent cell population in long-term (5-mo) regressed BCC (H\&E stain). (b-e) Immunofluorescence for keratins (anti-pan-keratin; green) and Ki67 (red), demonstrating extensive proliferation in untreated BCCs and the absence of detectable proliferation in longterm treated tumors (5-mo regressed BCC). Note the presence of Ki67-positive nuclei in the basal layer of the epidermis in both conditions (yellow arrowheads). $(f-i)$ Immunofluorescent images demonstrating keratins K1 or K17 (green) and DAPI nuclear counterstain (blue) in long-term regressed BCCs. $\mathrm{K} 17$ expression is present in nearly all tumor cells, while K1 was present focally in a subset of tumors treated with doxycycline for 5 mo. $(j, k)$ In situ hybridization illustrating the absence of Gli2 transgene expression [TRE-Gli2 (SV4O)] and presence of $K 17$ expression (blue) in residual tumor cells. Area of tumor in left panel delineated by black dashed line.
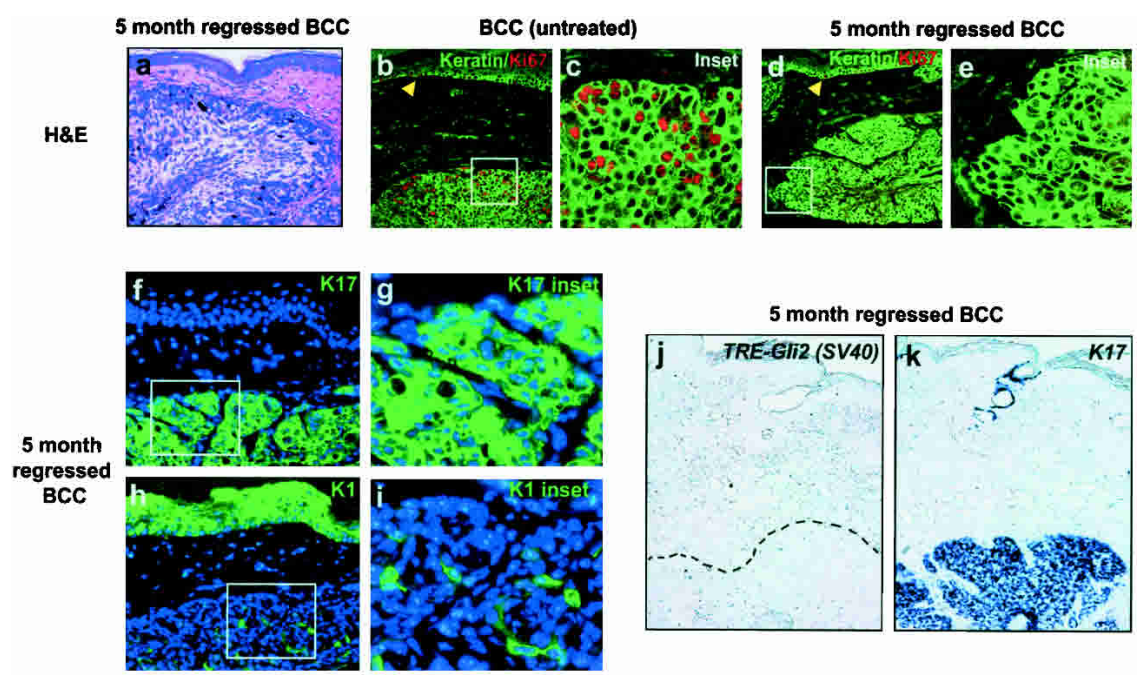


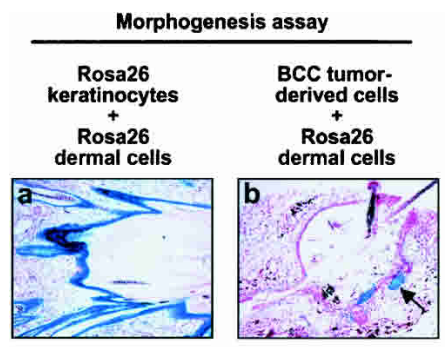

Hair bulb (hair matrix cells, dermal papilla)
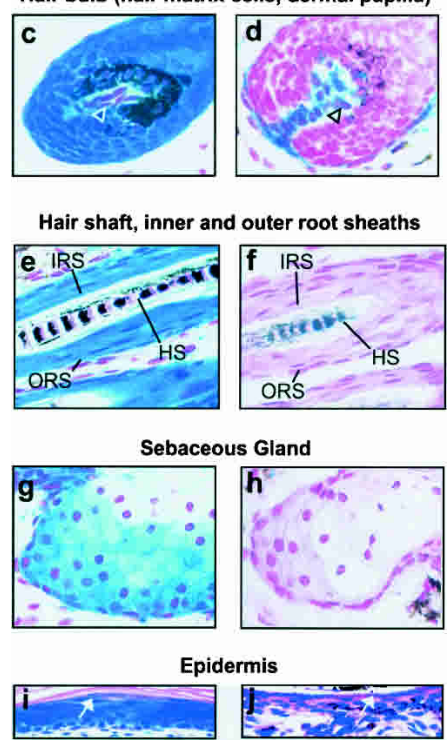

Figure 5. Regressing BCC tumor cells produce hair follicle and other epithelial lineages when combined with inductive dermal cells. Hair morphogenesis assays using inductive mesenchyme provided by newborn dermal cells from $\beta$-galactosidase-expressing Rosa26 mice. Epithelial cell component consisted either of newborn Rosa26 keratinocytes (left column) or BCC tumor-derived cells (right column). Mesenchymal-epithelial cell mixtures were injected subcutaneously into doxycycline-fed NODscid mice to inactivate Gli2 transgene expression, and grafts harvested 3 wk later. Tissue was whole-mount stained to detect $\beta$-galactosidase activity, and counterstained with either nuclear fast red (NFR, $a-h)$ or H\&E $(i, j) .(a, b)$ Hair follicles project into cystic cavities in assays containing either control keratinocytes or BCC tumor-derived cells. Note that in control assay (left column) all epithelial cells stain deep blue, whereas in BCCderived assay (right column) nearly all epithelial cells are $\beta$-galactosidase-negative, with the exception of focal staining $(b$, black arrow) consistent with the presence of a small number of contaminating Rosa26 keratinocytes in the dermal cell preparation. In BCC-derived assay, mature hair shafts are visible in the upper right corner of $b .(c, d)$ Hair bulbs demonstrating deepblue staining of follicular matrix cells and lighter staining of dermal papilla in control ( $c$, arrowhead). In BCC-derived assays, the relationship of the $\beta$-galactosidase-negative epithelial cells to the $\beta$-galactosidase-positive dermal papilla cells $(d$, arrowhead) is preserved. $(e, f)$ A mature-appearing hair shaft (HS) is present in both control and BCC-derived cell morphogenesis assays. In addition, inner and outer root sheath compartments (IRS and ORS) are present in controls $(e)$ and BCC-derived follicles $(f) .(g, h)$ Sebaceous glands were evident in both control and tumor-derived cell assays. $(i, j)$ Cyst lining showing keratohyaline granules characteristic of the epidermal granular cell layer (white arrows), in both control and BCC-derived assays. licle, maintains a strict dependence on the surrounding stromal environment of the skin (Miller 1995). Intriguingly, several aspects of $\mathrm{BCC}$ growth and regression in doxycycline-treated K5-tTA;TRE-Gli2 mice have parallels in the physiologic process of hair cycling (Stenn and Paus 2001). Hh pathway activation is important for postnatal follicle growth which is limited to the anagen phase of the hair cycle (Sato et al. 1999; Wang et al. 2000; Bergstein et al. 2002), and constitutive Hh pathway activation is seen in essentially all human BCCs and is likely to be required for tumor growth. BCC regression following transgene inactivation resembles follicle regression during the catagen phase of the hair cycle, when cell proliferation ceases and the entire follicular epithelium undergoes apoptosis, with the exception of the stem cell niche and follicle infundibulum (Muller-Rover et al. 2001). Long-term regressed tumor cells were quiescent and expressed K17 (Fig. 4f,g), and in this manner resembled the telogen outer root sheath, the location of the putative stem cell niche in the skin (Cotsarelis et al. 1990; Blanpain et al. 2004; Morris et al. 2004; Tumbar et al. 2004). Residual tumor cells remained quiescent, even

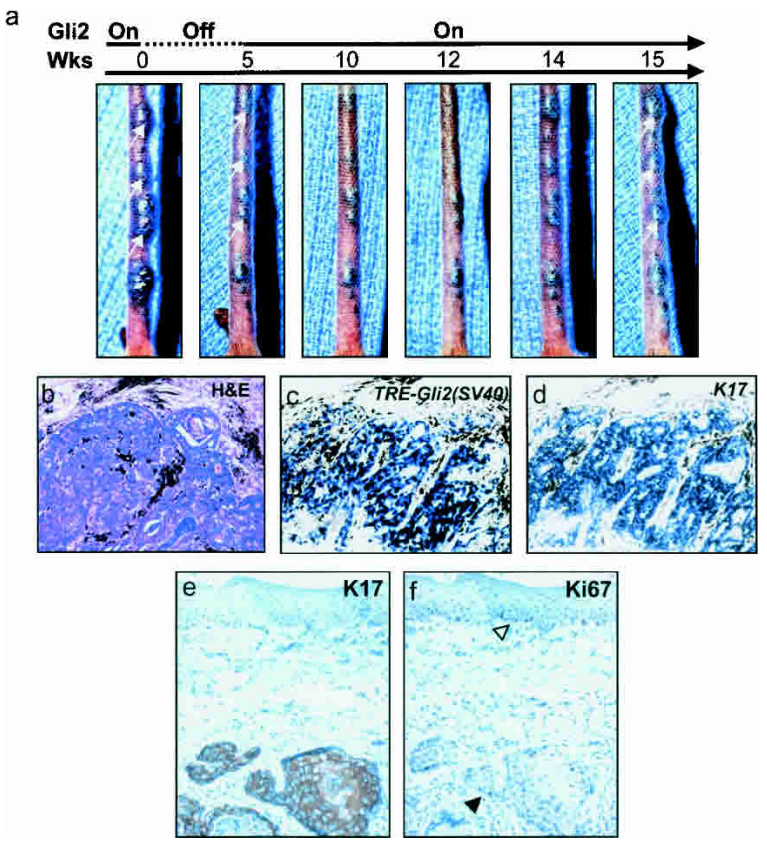

Figure 6. Reactivation of transgene in regressed tumors results in resumption of tumor growth. (a) Gross appearance of tumorbearing tail over a 15 -wk observation period, beginning with 5 wk of doxycycline treatment (Gli2 Off, dashed line). Note reduction in tumor size following doxycycline treatment, with regrowth of several tumors (white arrow, panel on far right) following discontinuation of doxycycline (Gli2 On, solid line). (b) Histology of regressed-reactivated tumor, with pigment (black) surrounding tumor nodules. $(c, d)$ In situ hybridization [TRE-Gli2 (SV4O)] showing expression of transgene and K17 in regressed-reactivated tumor following transgene reactivation. $(e, f)$ Immunohistochemistry for $\mathrm{K} 17$ and $\mathrm{Ki} 67$ in reactivated tumors. Tumors were positive for K17 expression. The basal layer of the epidermis was Ki67-positive ( $f$, open arrowhead) as was the reactivated tumor epithelium $(f$, black arrowhead). 
when doxycycline treatment was extended to a period of $1 \mathrm{yr}$ (data not shown). However, transgene reactivation in this quiescent population caused reinitiation of proliferation (Fig. 6a,e,f), suggesting that these cells retain their capacity to form tumors with the proper stimulus. On the other hand, when placed in an inductive environment with transgenic Gli2 expression extinguished, BCC cells were capable of differentiating into multiple epithelial cell lineages (Fig. 5). Interestingly, transplantation of embryonic mouse skin with BCC-like downgrowths from K14-SHH transgenic founders also leads to the formation of differentiated cell types (Oro et al. 1997), suggesting that in some settings, tissue microenvironment plays an important role in epithelial responsiveness to Hh signaling (Oro and Higgins 2003). Taken together, our data strongly suggest that a subset of BCCderived cells possesses properties that are characteristic of hair follicle stem cells (Oshima et al. 2001; Blanpain et al. 2004; Morris et al. 2004; Tumbar et al. 2004), including the ability to reinitiate growth after prolonged periods of quiescence, and to contribute to the formation of all epithelial cell lineages in skin.

Our findings are in keeping with results using embryonic and postnatal mouse skin explants to demonstrate the efficacy of Hh pathway inhibition in blocking growth of microscopic BCC-like tumors (Williams et al. 2003), as well as studies showing that pharmacological blockade of $\mathrm{Hh}$ signaling can reverse features of neoplasia in cultured cells and xenografts of other tumors characterized by deregulated Hh signaling (Berman et al. 2002; Berman et al. 2003; Thayer et al. 2003; Watkins et al. 2003). However, the persistence of a quiescent cell population in regressed BCCs suggests that even prolonged suppression of Hh signaling may not be sufficient to cause complete tumor regression. The reappearance of growing tumors following re-expression of Gli2 (Fig. 6) in "regressed" BCCs implies that long-term use of Hh pathway inhibitors may be required to prevent recurrence of established tumors.

\section{Materials and methods}

\section{Production of transgenic mice and transgene inactivation}

Protocols for mouse experimentation were approved by the University of Michigan Committee on the Use and Care of Animals. Characterization and use of skin-targeted conditional gene expression using K5-tTA transgenic mice, and the tetracycline response element (TRE) linked to a second transgene, were described (Kistner et al. 1996; Diamond et al. 2000). The TRE-Gli2 construct was created as follows: An XbaI-FauI fragment, including the bovine growth hormone polyA sequence, was removed from pTRE-2. Following ligation, this plasmid was digested with PvuII and ClaI, and an NruI-ClaI fragment containing Flag-Gli2 (Grachtchouk et al. 2000) and an SV40 poly A-intron sequence originally from K5pola (Brown et al. 1998) were inserted to generate TRE-Gli2. All cloning was verified by sequencing. A SapI-AatII fragment from TRE-Gli2 was purified and injected into (C57BL/6 X SJL) F2 mouse eggs by the University of Michigan Transgenic Core. TRE-Gli2 founders were crossed with C57BL/6 breeders (Jackson Labs), and two of 15 founders yielded lines of mice that produced BCCs when crossed with K5-tTA mice (Diamond et al. 2000). We focused on the TRE-Gli2 ${ }^{446}$ line for the studies in this report, which will be referred to simply as TRE-Gli2. Lines were maintained by serial crossing onto a C57BL/6 background (Charles River Labs). Genotyping was performed using transgene-specific primers to detect $t T A$ and the Flag-tagged Gli2 allele, with mouse $\beta$-globin as a positive control. Primer sequences and PCR conditions are available upon request.

Administration of doxycycline to tumor-bearing K5-tTA;TREGli2 double transgenic mice (6-12 mo of age) and control littermates was accomplished by providing doxycycline $(20 \mathrm{mg} / \mathrm{mL})$ in $5 \%$ sucrose in drinking water, and doxycycline-containing chow (Bio-serve, $200 \mathrm{mg} / \mathrm{kg}$ ). Mice received doxycycline in chow and drinking water ad lib for $3 \mathrm{~d}$, after which the mice were maintained on doxycycline chow for the time period specified. To rule out the possibility of a nonspecific effect of doxycycline on tumor growth, we fed doxycycline to BCC-bearing K5-Gli2 transgenic mice (Grachtchouk et al. 2000) and observed no reduction in BCC growth over a 6-mo period (data not shown). For reactivation experiments, tumor-bearing K5-tTA; TRE-Gli2 mice were photographed and fed doxycycline for a period of 5 or $6 \mathrm{wk}$. Subsequently, the doxycycline was discontinued and mice were followed for a 10-12-wk period during which serial photographs were obtained and tissue harvested as described below.

\section{Tissue harvesting and tumor monitoring}

For each time point of the 21-d regression experiment (Fig. 2) or 12 -wk inactivation-reactivation experiment, serial digital photographs were obtained following induction of anesthesia (ketamine $75 \mathrm{mg} / \mathrm{kg}$ and xylazine $5 \mathrm{mg} / \mathrm{kg}$, injected intraperitoneally). Tumor volume measurements (cubic millimeters) were obtained prior to initiation of doxycycline and at each subsequent time point using digital calipers. Average serial tumor measurements ( $n=3$ tumors per time point) were used to quantify changes in volume over the period of transgene inactivation. Selected tumors were removed from anesthetized mice with a scalpel such that a representative range of tumor sizes was included at each interval. Hemostasis was achieved by the application of direct pressure or aluminum chloride $135 \%$ aluminum chloride in $47.5 \% \mathrm{EtOH}$ ), when necessary. Specimens were trisected and either fixed overnight in neutral-buffered formalin (NBF), embedded in OCT, or processed for RNA extraction (described below).

\section{In situ hybridization}

Detailed protocols for in situ hybridization using NBF-fixed tissue are described elsewhere (Grachtchouk et al. 2003). The probes used in this study included a transgene-specific riboprobe designed to hybridize to the SV40 polyA sequence in TRE-Gli2 (Grachtchouk et al. 2003), and riboprobes to detect K17 (McGowan and Coulombe 1998; provided by P. Coulombe, Johns Hopkins University, Baltimore, MD), K15 (Liu et al. 2003; provided by G. Cotsarelis, University of Pennsylvania, Philadelphia, PA), Gli1, Gli2 and Ptch1 (Ding et al. 1998; provided by C-c. Hui, University of Toronto, Ontario, Canada).

\section{RT-PCR}

Tumor specimens for RNA extraction were microdissected to remove the overlying epidermis, homogenized in Trizol (Invitrogen), and stored at $-70^{\circ} \mathrm{C}$ until further processing. RNA isolation, first-strand cDNA synthesis, and RT-PCR were per- 
formed as described (Allen et al. 2003). Primer sequences and PCR parameters are available upon request.

\section{Immunostaining and TUNEL assay}

Tissue samples fixed in NBF and paraffin-embedded were used for all immunofluorescence and TUNEL staining. For immunofluorescence, following citrate-buffer antigen retrieval, sections were blocked in $10 \%$ normal goat serum (NGS) in phosphatebuffered saline (PBS) and incubated with the following antibodies: K17 (kindly provided by P. Coulombe) 1:2000; Ki67 (Novo Castra) 1:500; Pan-Keratin (Neomarkers) 1:100; K1 (Covance) 1:1000. All antibodies are rabbit polyclonal with the exception of Pan-Keratin, which is a mouse monoclonal. Fluorescent secondary antibodies (Jackson Labs) were used at 1:75 dilution. For immunohistochemistry, pigment was sometimes removed from paraffin sections with $\mathrm{H}_{2} \mathrm{O}_{2}$ as described (Li et al. 1999). Blocking was performed using $1.5 \%$ NGS in PBS, and antibodies were visualized using DAB following the Vectastain Peroxidase ABC Standard kit (Vector Labs), with a hematoxylin counterstain. TUNEL assay was performed on paraffin sections without antigen retrieval following the manufacturer's instructions (Apoptag Red Kit, Intergen) with the omission of proteinase $\mathrm{K}$ treatment. Sections were mounted with DAPI-containing fluorescent mounting media. Quantification of proliferation and apoptotic nuclei was accomplished by performing counts for DAPI and Ki67 or TUNEL. Nuclei were counted manually using digital photography and Adobe Photoshop software. Average counts were determined using three tumors per time point, with 10 high-powered fields counted per tumor.

\section{Hair morphogenesis assay}

NOD-scid mice (female, 10-12-wk-old) were premedicated with VP-16 (etoposide, $30 \mathrm{mg} / \mathrm{kg}$ IP injection) (Al Haji et al. 2003) and fed doxycycline chow $5 \mathrm{~d}$ prior to injection. $\beta$-galactosidasepositive primary dermal cells and keratinocytes were prepared from skin of newborn Rosa26 mice (Zambrowicz et al. 1997) using established methods (Dlugosz et al. 1995), and grown in vitro for $2-5 \mathrm{~d}$ prior to use in morphogenesis assays. To assess whether regressing tumor cells could give rise to multiple cell lineages, BCCs $\left(\sim 50 \mathrm{~mm}^{3}\right)$ were obtained from tumor-bearing K5-tTA;TRE-Gli2 mice and, under sterile conditions, minced into small fragments in Hanks balanced salt solution. Fragments were drawn into a syringe via an 18-gauge needle and mixed with primary Rosa26 dermal cells $\left(5 \times 10^{6}\right.$ cells $)$, followed by subcutaneous injection into NOD-scid mice that were treated as outlined above, and fed doxycycline chow to inactivate Gli2 expression. As a positive control, primary Rosa26 keratinocytes $\left(5 \times 10^{6}\right.$ cells $)$ and Rosa26 dermal cells were combined and injected in a similar manner. Negative control grafts contained Rosa26 dermal cells combined either with cells from the undersurface of control adult mouse tail skin, or keratinocytes isolated from adult mouse tail skin. Doxycycline administration was continued for 3 wk to maintain transgene inactivation in regressing tumor cells, at which time the animals were sacrificed. Graft sites were fixed in $4 \%$ paraformaldehyde for whole-mount detection of $\beta$-galactosidase activity, using 1 $\mathrm{mg} / \mathrm{mL}$ X-gal solution at $37^{\circ} \mathrm{C}$ for $24 \mathrm{~h}$. Specimens were embedded in paraffin and stained with either nuclear fast red (NFR) or hematoxylin and eosin (H\&E).

\section{Acknowledgments}

We thank the University of Michigan Transgenic Core, particularly Dr. Margaret Van Keuren, for production of TRE-Gli2 founders; Dr. Ulrike Lichti for valuable advice regarding hair follicle morphogenesis assays; Dr. Muhammad Al-Hajj for assistance with NOD-scid mouse experiments; Drs. Pierre Coulombe, George Cotsarelis, and Chi-chung Hui for reagents; and Drs. Sean Morrison, Theo Ross, Max Wicha, and Sarah Millar for comments on the manuscript. This work was performed using funds from NIH grants CA87837, AR45973, and CA46592. M.H. was supported by a training grant (AR07197).

\section{References}

Al Haji, M., Wicha, M.S., Benito-Hernandez, A., Morrison, S.J., and Clarke, M.F. 2003. Prospective identification of tumorigenic breast cancer cells. Proc. Natl. Acad. Sci. 100: 39833988.

Allen, M., Grachtchouk, M., Sheng, H., Grachtchouk, V., Wang, A., Wei, L., Liu, J., Ramirez, A., Metzger, D., Chambon, P., et al. 2003. Hedgehog signaling regulates sebaceous gland development. Am. I. Pathol. 163: 2173-2178.

Aszterbaum, M., Epstein, J., Oro, A., Douglas, V., LeBoit, P.E., Scott, M.P., and Epstein Jr., E.H. 1999. Ultraviolet and ionizing radiation enhance the growth of BCCs and trichoblastomas in patched heterozygous knockout mice. Nat. Med. 5: 1285-1291.

Bai, C.B., Auerbach, W., Lee, J.S., Stephen, D., and Joyner, A.L. 2002. Gli2, but not Gli1, is required for initial Shh signaling and ectopic activation of the Shh pathway. Development 129: 4753-4761.

Bale, A.E. and Yu, K.P. 2001. The hedgehog pathway and basal cell carcinomas. Hum. Mol. Genet. 10: 757-762.

Bergstein, I., Leopold, P., Sato, N., Panteleyev, A., Christiano, A., and Crystal, R. 2002. In vivo enhanced expression of patched dampens the sonic hedgehog pathway. Mol. Ther. 6: 258-264.

Berman, D.M., Karhadkar, S.S., Hallahan, A.R., Pritchard, J.I., Eberhart, C.G., Watkins, D.N., Chen, J.K., Cooper, M.K., Taipale, J., Olson, J.M., et al. 2002. Medulloblastoma growth inhibition by hedgehog pathway blockade. Science 297: 1559-1561.

Berman, D.M., Karhadkar, S.S., Maitra, A., Montes, D.O., Gerstenblith, M.R., Briggs, K., Parker, A.R., Shimada, Y., Eshleman, J.R., Watkins, D.N., et al. 2003. Widespread requirement for Hedgehog ligand stimulation in growth of digestive tract tumours. Nature 425: 846-851.

Blanpain, C., Lowry, W.E., Geoghegan, A., Polak, L., and Fuchs, E. 2004. Self-renewal, multipotency, and the existence of two cell populations within an epithelial stem cell niche. Cell 118: 635-648.

Brown, K., Strathdee, D., Bryson, S., Lambie, W., and Balmain, A. 1998. The malignant capacity of skin tumours induced by expression of a mutant H-ras transgene depends on the cell type targeted. Curr. Biol. 8: 516-524.

Chiang, C., Swan, R.Z., Grachtchouk, M., Bolinger, M., Litingtung, Y., Robertson, E.K., Cooper, M.K., Gaffield, W., Westphal, H., Beachy, P.A., et al. 1999. Essential role for Sonic hedgehog during hair follicle morphogenesis. Dev. Biol. 205: $1-9$.

Chin, L., Tam, A., Pomerantz, J., Wong, M., Holash, J., Bardeesy, N., Shen, Q., O’Hagan, R., Pantginis, J., Zhou, H., et al. 1999. Essential role for oncogenic Ras in tumour maintenance. Nature 400: 468-472.

Clark, J.C., Tichelaar, J.W., Wert, S.E., Itoh, N., Perl, A.K., Stahlman, M.T., and Whitsett, J.A. 2001. FGF-10 disrupts lung morphogenesis and causes pulmonary adenomas in vivo. Am. J. Physiol. Lung Cell Mol. Physiol. 280: L705-L715. 
Cotsarelis, G., Sun, T.T., and Lavker, R.M. 1990. Label-retaining cells reside in the bulge area of pilosebaceous unit: Implications for follicular stem cells, hair cycle, and skin carcinogenesis. Cell 61: 1329-1337.

D'Cruz, C.M., Gunther, E.J., Boxer, R.B., Hartman, J.L., Sintasath, L., Moody, S.E., Cox, J.D., Ha, S.I., Belka, G.K., Golant, A., et al. 2001. c-MYC induces mammary tumorigenesis by means of a preferred pathway involving spontaneous Kras2 mutations. Nat. Med. 7: 235-239.

Diamond, I., Owolabi, T., Marco, M., Lam, C., and Glick, A. 2000. Conditional gene expression in the epidermis of transgenic mice using the tetracycline-regulated transactivators tTA and rTA linked to the keratin 5 promoter. I. Invest. Dermatol. 115: 788-794.

Ding, Q., Motoyama, J., Gasca, S., Mo, R., Sasaki, H., Rossant, J., and Hui, C.C. 1998. Diminished Sonic hedgehog signaling and lack of floor plate differentiation in Gli2 mutant mice. Development 125: 2533-2543.

Dlugosz, A.A., Glick, A.B., Tennenbaum, T., Weinberg, W.C., and Yuspa, S.H. 1995. Isolation and utilization of epidermal keratinocytes for oncogene research. Methods Enzymol. 254: 3-20.

Ewald, D., Li, M., Efrat, S., Auer, G., Wall, R.J., Furth, P.A., and Hennighausen, L. 1996. Time-sensitive reversal of hyperplasia in transgenic mice expressing SV40 T antigen. Science 273: $1384-1386$.

Felsher, D.W. 2003. Cancer revoked: Oncogenes as therapeutic targets. Nat. Rev. Cancer 3: 375-380.

Felsher, D.W. and Bishop, J.M. 1999. Reversible tumorigenesis by MYC in hematopoietic lineages. Mol. Cell 4: 199-207.

Fisher, G.H., Wellen, S.L., Klimstra, D., Lenczowski, J.M., Tichelaar, J.W., Lizak, M.J., Whitsett, J.A., Koretsky, A., and Varmus, H.E. 2001. Induction and apoptotic regression of lung adenocarcinomas by regulation of a K-Ras transgene in the presence and absence of tumor suppressor genes. Genes \& Dev. 15: 3249-3262.

Grachtchouk, M., Mo, R., Yu, S., Zhang, X., Sasaki, H., Hui, C.C., and Dlugosz, A.A. 2000. Basal cell carcinomas in mice overexpressing Gli2 in skin. Nat. Genet. 24: 216-217.

Grachtchouk, V., Grachtchouk, M., Lowe, L., Johnson, T., Wei, L., Wang, A., de Sauvage, F., and Dlugosz, A.A. 2003. The magnitude of hedgehog signaling activity defines skin tumor phenotype. EMBO J. 22: 2741-2751.

Gunther, E.J., Moody, S.E., Belka, G.K., Hahn, K.T., Innocent, N., Dugan, K.D., Cardiff, R.D., and Chodosh, L.A. 2003. Impact of p53 loss on reversal and recurrence of conditional Wnt-induced tumorigenesis. Genes \& Dev. 17: 488501.

Hahn, H., Wicking, C., Zaphiropoulous, P.G., Gailani, M.R., Shanley, S., Chidambaram, A., Vorechovsky, I., Holmberg, E., Unden, A.B., Gillies, S., et al. 1996. Mutations of the human homolog of Drosophila patched in the nevoid basal cell carcinoma syndrome. Cell 85: 841-851.

Hardcastle, Z., Mo, R., Hui, C.C., and Sharpe, P.T. 1998. The Shh signalling pathway in tooth development: Defects in Gli2 and Gli3 mutants. Development 125: 2803-2811.

Huettner, C.S., Zhang, P., Van Etten, R.A., and Tenen, D.G. 2000. Reversibility of acute B-cell leukaemia induced by BCR-ABL1. Nat. Genet. 24: 57-60.

Ingham, P.W. and McMahon, A.P. 2001. Hedgehog signaling in animal development: Paradigms and principles. Genes \& Dev. 15: 3059-3087.

Jain, M., Arvanitis, C., Chu, K., Dewey, W., Leonhardt, E., Trinh, M., Sundberg, C.D., Bishop, J.M., and Felsher, D.W. 2002. Sustained loss of a neoplastic phenotype by brief inactivation of MYC. Science 297: 102-104.
Jih, D.M., Lyle, S., Elenitsas, R., Elder, D.E., and Cotsarelis, G. 1999. Cytokeratin 15 expression in trichoepitheliomas and a subset of basal cell carcinomas suggests they originate from hair follicle stem cells. J. Cutan. Pathol. 26: 113-118.

Johnson, R.L., Rothman, A.L., Xie, J., Goodrich, L.V., Bare, J.W., Bonifas, J.M., Quinn, A.G., Myers, R.M., Cox, D.R., Epstein Jr., E.H., et al. 1996. Human homolog of patched, a candidate gene for the basal cell nevus syndrome. Science 272: 1668 1671.

Kamimura, J., Lee, D., Baden, H.P., Brissette, J., and Dotto, G.P. 1997. Primary mouse keratinocyte cultures contain hair follicle progenitor cells with multiple differentiation potential. J. Invest. Dermatol. 109: 534-540.

Karlsson, A., Giuriato, S., Tang, F., Fung-Weier, J., Levan, G., and Felsher, D.W. 2003. Genomically complex lymphomas undergo sustained tumor regression upon MYC inactivation unless they acquire novel chromosomal translocations. Blood 101: 2797-2803.

Kistner, A., Gossen, M., Zimmermann, F., Jerecic, J., Ullmer, C., Lubbert, H., and Bujard, H. 1996. Doxycycline-mediated quantitative and tissue-specific control of gene expression in transgenic mice. Proc. Natl. Acad. Sci. 93: 10933-10938.

Li, L.X., Crotty, K.A., Kril, J.J., Palmer, A.A., and McCarthy, S.W. 1999. Method of melanin bleaching in MIB1-Ki67 immunostaining of pigmented lesions: A quantitative evaluation in malignant melanomas. Histochem. J. 31: 237-240.

Lichti, U., Weinberg, W.C., Goodman, L., Ledbetter, S., Dooley, T., Morgan, D., and Yuspa, S.H. 1993. In vivo regulation of murine hair growth: Insights from grafting defined cell populations onto nude mice. J. Invest. Dermatol. 101: 124S-129S.

Liu, Y, Lyle, S., Yang, Z, and Cotsarelis, G. 2003. Keratin 15 promoter targets putative epithelial stem cells in the hair follicle bulge. J. Invest. Dermatol. 121: 963-968.

Lyle, S., Christofidou-Solomidou, M., Liu, Y., Elder, D.E., Albelda, S., and Cotsarelis, G. 1999. Human hair follicle bulge cells are biochemically distinct and possess an epithelial stem cell phenotype. I. Invest. Dermatol. Symp. Proc. 4: 296-301.

Matise, M.P., Epstein, D.J., Park, H.L., Platt, K.A., and Joyner, A.L. 1998. Gli2 is required for induction of floor plate and adjacent cells, but not most ventral neurons in the mouse central nervous system. Development 125: 2759-2770.

McGowan, K.M. and Coulombe, P.A. 1998. Onset of keratin 17 expression coincides with the definition of major epithelial lineages during skin development. J. Cell Biol. 143: 469486.

McMahon, A.P., Ingham, P.W., and Tabin, C.J. 2003. Developmental roles and clinical significance of hedgehog signaling. Curr. Top. Dev. Biol. 53: 1-114.

Mill, P., Mo, R., Fu, H., Grachtchouk, M., Kim, P.C., Dlugosz, A.A., and Hui, C.C. 2003. Sonic hedgehog-dependent activation of Gli2 is essential for embryonic hair follicle development. Genes \& Dev. 17: 282-294.

Miller, S.J. 1995. Etiology and pathogenesis of basal cell carcinoma. Clin. Dermatol. 13: 527-536.

Mo, R., Freer, A.M., Zinyk, D.L., Crackower, M.A., Michaud, J., Heng, H.H., Chik, K.W., Shi, X.M., Tsui, L.C., Cheng, S.H., et al. 1997. Specific and redundant functions of Gli2 and Gli3 zinc finger genes in skeletal patterning and development. Development 124: 113-123.

Moody, S.E., Sarkisian, C.J., Hahn, K.T., Gunther, E.J., Pickup, S., Dugan, K.D., Innocent, N., Cardiff, R.D., Schnall, M.D., and Chodosh, L.A. 2002. Conditional activation of Neu in the mammary epithelium of transgenic mice results in reversible pulmonary metastasis. Cancer Cell 2: 451-461.

Morris, R.J., Liu, Y., Marles, L., Yang, Z., Trempus, C., Li, S., 
Lin, J.S., Sawicki, J.A., and Cotsarelis, G. 2004. Capturing and profiling adult hair follicle stem cells. Nat. Biotechnol. 22: 411-417.

Motoyama, J., Liu, J., Mo, R., Ding, Q., Post, M., and Hui, C.C. 1998. Essential function of Gli2 and Gli3 in the formation of lung, trachea and oesophagus. Nat. Genet. 20: 54-57.

Muller-Rover, S., Handjiski, B., van der Veen, C., Eichmuller, S., Foitzik, K., McKay, I.A., Stenn, K.S., and Paus, R. 2001. A comprehensive guide for the accurate classification of murine hair follicles in distinct hair cycle stages. J. Invest. Dermatol. 117: 3-15.

Nilsson, M., Unden, A.B., Krause, D., Malmqwist, U., Raza, K., Zaphiropoulos, P.G., and Toftgard, R. 2000. Induction of basal cell carcinomas and trichoepitheliomas in mice overexpressing GLI-1. Proc. Nat1. Acad. Sci. 97: 3438-3443.

Oro, A.E. and Higgins, K. 2003. Hair cycle regulation of Hedgehog signal reception. Dev. Biol. 255: 238-248.

Oro, A.E., Higgins, K.M., Hu, Z., Bonifas, J.M., Epstein Jr., E.H., and Scott, M.P. 1997. Basal cell carcinomas in mice overexpressing sonic hedgehog. Science 276: 817-821.

Oshima, H., Rochat, A., Kedzia, C., Kobayashi, K., and Barrandon, Y. 2001. Morphogenesis and renewal of hair follicles from adult multipotent stem cells. Cell 104: 233-245.

Pardal, R., Clarke, M.F., and Morrison, S.J. 2003. Applying the principles of stem-cell biology to cancer. Nat. Rev. Cancer 3: 895-902.

Pasca di Magliano, M. and Hebrok, M. 2003. Hedgehog signalling in cancer formation and maintenance. Nat. Rev. Cancer 3: 903-911.

Pelengaris, S., Littlewood, T., Khan, M., Elia, G., and Evan, G. 1999. Reversible activation of c-Myc in skin: Induction of a complex neoplastic phenotype by a single oncogenic lesion. Mol. Cell 3: 565-577.

Pelengaris, S., Khan, M., and Evan, G.I. 2002. Suppression of Myc-induced apoptosis in $\beta$ cells exposes multiple oncogenic properties of Myc and triggers carcinogenic progression. Cell 109: 321-334.

Prouty, S.M., Lawrence, L., and Stenn, K.S. 1997. Fibroblastdependent induction of a murine skin lesion similar to human nevus sebaceus of Jadassohn. Lab. Invest. 76: 179-189.

Sato, N., Leopold, P.L., and Crystal, R.G. 1999. Induction of the hair growth phase in postnatal mice by localized transient expression of Sonic hedgehog. J. Clin. Invest. 104: 855-864.

Sheng, H., Goich, S., Wang, A., Grachtchouk, M., Lowe, L., Mo, R., Lin, K., de Sauvage, F.J., Sasaki, H., Hui, C.C., et al. 2002. Dissecting the oncogenic potential of Gli2: Deletion of an $\mathrm{NH}(2)$-terminal fragment alters skin tumor phenotype. Cancer Res. 62: 5308-5316.

St. Jacques, B., Dassule, H.R., Karavanova, I., Botchkarev, V.A., Li, J., Danielian, P.S., McMahon, J.A., Lewis, P.M., Paus, R., and McMahon, A.P. 1998. Sonic hedgehog signaling is essential for hair development. Curr. Biol. 8: 1058-1068.

Stenn, K.S. and Paus, R. 2001. Controls of hair follicle cycling. Physiol. Rev. 81: 449-494.

Thayer, S.P., di Magliano, M.P., Heiser, P.W., Nielsen, C.M., Roberts, D.J., Lauwers, G.Y., Qi, Y.P., Gysin, S., Fernandezdel Castillo, C., Yajnik, V., et al. 2003. Hedgehog is an early and late mediator of pancreatic cancer tumorigenesis. $\mathrm{Na}$ ture 425: 851-856.

Tumbar, T., Guasch, G., Greco, V., Blanpain, C., Lowry, W.E., Rendl, M., and Fuchs, E. 2004. Defining the epithelial stem cell niche in skin. Science 303: 359-363.

Wang, L.C., Liu, Z.Y., Gambardella, L., Delacour, A., Shapiro, R., Yang, J., Sizing, I., Rayhorn, P., Garber, E.A., Benjamin, C.D., et al. 2000. Regular articles: Conditional disruption of hedgehog signaling pathway defines its critical role in hair development and regeneration. I. Invest. Dermatol. 114: 901-908.

Wang, R., Ferrell, L.D., Faouzi, S., Maher, J.J., and Bishop, J.M. 2001. Activation of the Met receptor by cell attachment induces and sustains hepatocellular carcinomas in transgenic mice. J. Cell Biol. 153: 1023-1034.

Watkins, D.N., Berman, D.M., Burkholder, S.G., Wang, B., Beachy, P.A., and Baylin, S.B. 2003. Hedgehog signalling within airway epithelial progenitors and in small-cell lung cancer. Nature 422: 313-317.

Williams, J.A., Guicherit, O.M., Zaharian, B.I., Xu, Y., Chai, L., Wichterle, H., Kon, C., Gatchalian, C., Porter, J.A., Rubin, L.L., et al. 2003. Identification of a small molecule inhibitor of the hedgehog signaling pathway: Effects on basal cell carcinoma-like lesions. Proc. Natl. Acad. Sci. 100: 4616-4621.

Xie, J., Murone, M., Luoh, S.M., Ryan, A., Gu, Q., Zhang, C., Bonifas, J.M., Lam, C.W., Hynes, M., Goddard, A., et al. 1998. Activating Smoothened mutations in sporadic basalcell carcinoma. Nature 391: 90-92.

Zambrowicz, B.P., Imamoto, A., Fiering, S., Herzenberg, L.A., Kerr, W.G., and Soriano, P. 1997. Disruption of overlapping transcripts in the ROSA $\beta$ geo 26 gene trap strain leads to widespread expression of $\beta$-galactosidase in mouse embryos and hematopoietic cells. Proc. Natl. Acad. Sci. 94: 37893794 . 


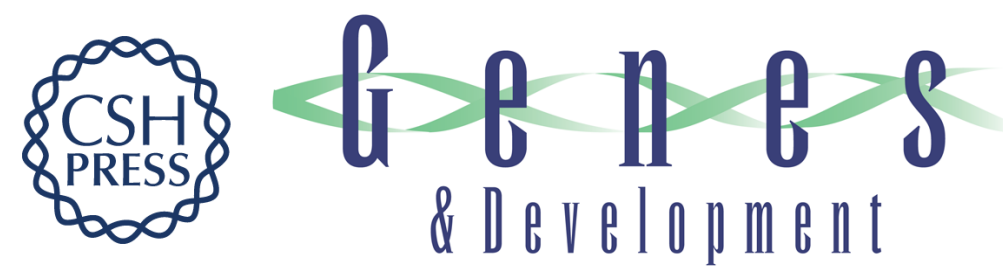

\section{Sustained Hedgehog signaling is required for basal cell carcinoma proliferation and survival: conditional skin tumorigenesis recapitulates the hair growth cycle}

Mark E. Hutchin, Muhammed S.T. Kariapper, Marina Grachtchouk, et al.

Genes Dev. 2005, 19:

Access the most recent version at doi:10.1101/gad.1258705

References This article cites 69 articles, 24 of which can be accessed free at: http://genesdev.cshlp.org/content/19/2/214.full.html\#ref-list-1

License

Email Alerting

Receive free email alerts when new articles cite this article - sign up in the box at the top Service right corner of the article or click here.

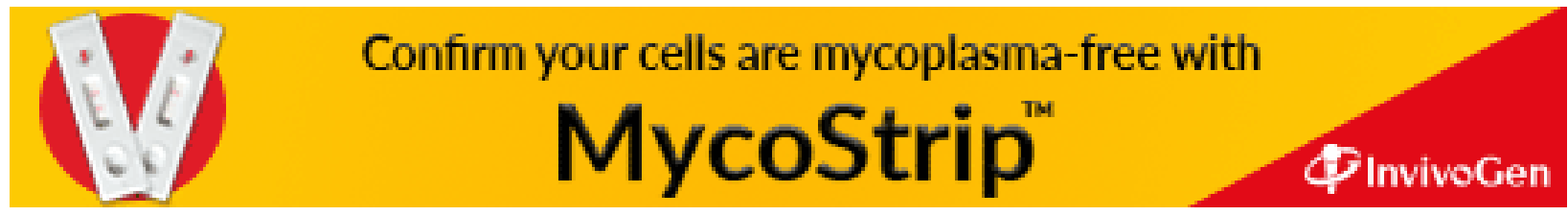

